\title{
The Structure of Plato's Dialogues and Greek Music Theory: A Response to J. B. Kennedy
}

\section{Citation}

Mckay, John Z., and Alexander Rehding. 2011. "The Structure of Plato's Dialogues and Greek Music Theory: A Response to J. B. Kennedy." Apeiron 44, no. 4.

\section{Published Version}

doi:10.1515/apeiron.2011.021

\section{Permanent link}

http://nrs.harvard.edu/urn-3:HUL.InstRepos:12712855

\section{Terms of Use}

This article was downloaded from Harvard University's DASH repository, and is made available under the terms and conditions applicable to Open Access Policy Articles, as set forth at http:// nrs.harvard.edu/urn-3:HUL.InstRepos:dash.current.terms-of-use\#OAP

\section{Share Your Story}

The Harvard community has made this article openly available.

Please share how this access benefits you. Submit a story.

Accessibility 


\section{The Structure of Plato's Dialogues and Greek Music Theory:}

\section{A Response to J. B. Kennedy}

John Z. McKay and Alexander Rehding

In his recent article, "Plato’s Forms, Pythagorean Mathematics, and Stichometry,” J. B. Kennedy suggests a new stichometric reading of the Platonic dialogues that follows a secret musical code. Kennedy argues in his central claim:

The twelve-part structure of the dialogues detected above together with the prominence of the number twelve in Greek music theory suggests that the stichometric structure of the dialogues is a musical scale. Plato used this musical scale as an outline, pegging key concepts and turns in the argument to steps in the scale. (pp. 16-17)

This idea is of considerable interest to music historians. As music theorists, we welcome this innovative interpretation, not least because of the attention it gives to Ancient Greek music theory - an area of study that is as marginal within modern musicology as it is within classical studies.

Kennedy is not the first to suspect a musical undercurrent in Plato's work. The nineteenth-century German politician and scholar Albert von Thimus, for instance, developed an esoteric music theory on the basis of Platonic-Pythagorean principles in his Die harmonikale Symbolik des Althertums (2 vols, 1868 and 1876). More recently, the musicologist Ernest McClain argued in 1978 that "Plato's Republic embodies a treatise on equal temperament," an important modern musical tuning system. ${ }^{1}$ The essential difference between these earlier efforts and Kennedy's work is that the former start out 
from music-theoretical principles that they sought to apply to Plato's texts, whereas Kennedy attaches principal significance to the number of lines and distribution of topics.

While Kennedy's stichometric analysis of the Platonic dialogues highlights a new dimension that may open up a wholly new interpretive realm of the texts, we shall use this opportunity to clarify a few of the music-theoretical concepts on which Kennedy draws in his work. These primary concerns include the significance of the number 12 within Greek music theory, the difference between ratios and numbers, and the contrast between musical and spatial distance. As we will see, the concept of the scale on which Kennedy bases his interpretation is not without problems, nor is the mapping of Greek music theory onto his system as simple and straightforward as it may at first appear.

\section{Scales}

First a few clarifying words. When Kennedy invokes a "twelve-note scale" (p. 17), this may sound like a familiar term, probably because of the "twelve-tone music" of earlyand mid-twentieth century Europe and America. Such music_-as well as that of the previous generation of composers, such as Richard Wagner, Franz Liszt, and Alexander

Scriabin - relies on the twelve semitones that we find, for instance, in the arrangement of the black and white keys of the piano keyboard within the span of an octave. These twelve tones make up the entire stockpile of pitch $^{2}$ material that we use in modern Western music; the scale made up of these twelve pitches is usually called "chromatic" (or sometimes even "pan-chromatic"), as shown in Example 1. 


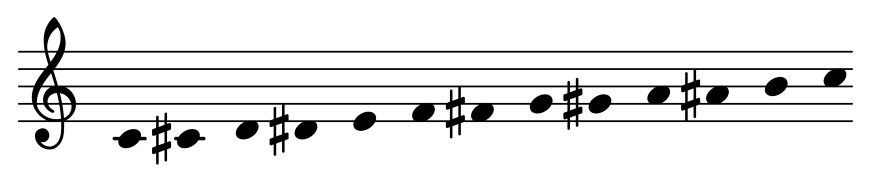

\section{Ex. 1: The modern chromatic scale contains twelve equally spaced elements}

Although Greek music theory also had a conception of chromaticism, the modern chromatic scale has little to do with the ancient conception: the tuning system underlying the modern chromatic scale—equal temperament—specifies that each chromatic semitone be based on a factor of the twelfth root of 2 . This is an irrational number that would have been unimaginable in Ancient Greece (which was a big stumbling block for accepting McClain's earlier thesis).

In fact, the very term "scale" is not without problems in Greek music theory. The term, in its modern usage, describes an ordered ascending or descending collection of pitch material in fixed intervals. ${ }^{3}$ Scales form a repository from which melodies (as well as harmonies) can be constructed. A large number of melodies are therefore based on a relatively small number of common scales. Very often the use of a particular scale implies a commitment to this scale's particular hierarchies or conventions (e.g. typical points of repose or centers of attraction, characteristic opening intervals or closing gestures).

Beyond these general features of scales, a number of properties are notable in modern western music, where scales count as a well-founded concept: scales tend to be restricted to a small number of possible intervals between adjacent elements (e.g. semitones and tones, or tones and minor thirds), which often endows them with particular properties. Moreover, they are typically confined to the range of one octave, beyond which their 
properties repeat. We draw attention to these more rigorous, systematizing aspects of scale theory because it is the systematizing aspects of the scale that play a prominent role in Kennedy's argument. In other words, while any melodic material can be "ordered" into scales of pitch material on which these melodies are based, a concept of scale becomes meaningful if it has properties that can be generalized and mathematically described. This systematic potential is apparently a major impetus for Kennedy's use of this term, as he draws particular attention to the "harmonic structure of the underlying musical scale" (p. $17) .^{4}$

To recall the basics of Greek music theory, scales work a bit differently from our modern conception. ${ }^{5}$ The basic building block of these scales is the tetrachord, a grouping of four tones that always span the interval of the perfect fourth (or diatessaron). The outer tones of these tetrachords are fixed, whereas the inner ones are moveable. The placement (and tuning) of these inner tones depends on the genus - diatonic, chromatic, enharmonic - to which the scale system belongs. Different theorists specify different ways to determine these inner tones, but all theorists are in agreement that in all three genera the placement of these inner tones will subdivide the fourth so as to produce smaller intervals that are never all equal in size. Moreover, these building blocks never have more than four tones within the compass of the fourth; a chromatic arrangement in the modern sense-which would require five equally spaced semitones in the tetrachord and twelve in the octavedoes not exist in a practical musical scale for the Greeks. ${ }^{6}$

These tetrachords are then connected in various ways - by synaphe or diazeuxis - either directly or with one interspersed whole tone. Such systems do not stop at the octave: the Greater Perfect System (systema teleion meizon) spans two full octaves (15 pitches) and 
the Lesser Perfect System (systema teleion elatton) spans one-and-a-half octaves (11 pitches).

Greek music theory offers a number of other concepts - tonoi, harmoniai - that are scalelike constructs, but we probably do not need to go through these here in any detail, since none of them possesses the required properties of having twelve equidistant elements. When Kennedy refers to a "musical scale with twelve regularly spaced notes" (p. 21) that corresponds to the twelve-part structure he observes in the Platonic dialogues, it remains unclear what exactly Kennedy is referring to. It seems that the modern chromatic scale with its evenly spaced semitones would be the closest scale equivalent but this option was, as mentioned, not available to Plato and his age. On closer inspection, it seems unlikely that what Kennedy has in mind is a scale-like formation in any conventional sense.

\section{Ratios and Numbers}

Kennedy may give us a hint what he has in mind when he explains: "According to Greek theory, the third (1:4), fourth (1:3), sixth (1:2), eighth $(2: 3)$, and ninth (3:4) notes on the twelve-note scale will harmonise with the twelfth" (p. 17). What matters, as becomes clear from the argument, is the property of being divisible by twelve. There is no common musical term for such a set of intervals; while this is not a scale, it can be described as a series of ratios.

Two preliminary points are important. First, ratios are not the same as cardinal or ordinal numbers. Mathematically speaking, they are abstract representations of a potential class 
of relationships between sets of quantities. For example, the 6:12 ratio that Kennedy correctly identifies as an octave (p. 16) is not a unique representation. ${ }^{7}$ The ratios $1: 2$, $2: 4,3: 6,4: 8$, and $5: 10$ (all potentially found in his twelve-note system by comparing pairs of notes) are also equally valid ways of writing the same ratio, since they all are multiples of each other.

And second, ratios have different properties and require different algorithms for operations than ordinary numbers. To "add" two ratios is to use an algorithm that looks more like multiplying fractions to us. To add the octave $3: 6$ and the octave $6: 12$, for example, one obtains $(3: 6) \times(6: 12)=18: 72$, or $1: 4$ in reduced form, creating a doubleoctave. $^{8}$

This is perhaps the fundamental point that could create confusion between an equally spaced twelve-note modern chromatic scale and a set of intervals represented by the ratios $1: 12,2: 12,3: 12, \ldots 12: 12$. To use a simple analogy, if the octave is represented by a pie, the modern chromatic scale could be considered a way of dividing the pie into 12 equal slices. At first glance, the series of ratios (which look like fractions) appears to follow a similar idea. However, Kennedy's octave ratio 6:12, for example, does not refer to the sixth slice of a pie. It is instead the ratio of six slices of a pie to the entire pie. Thus, in Kennedy's model the octave is not represented by the entire equally-divided pie itself, but rather by a ratio between certain fractions of the pie. To treat the ratio 6:12 as equivalent to the sixth slice of a pie (or the sixth note in a twelve-note scale or the sixth division in a Platonic dialogue) is to equate fundamentally incommensurable entities. 
That said, Kennedy is right to point out the importance of ratios in Greek musical thought. In the Pythagorean tradition, musical intervals are indeed identified in terms of ratios. The ratios of 6:8:9:12 that Kennedy invokes in his article (p. 16) could be understood as such a system of two disconnected tetrachords, where the lower

diatessaron $(6: 8=3: 4)^{9}$ is separated by a whole-tone diazeuxis $(8: 9),{ }^{10}$ which then marks the starting point of a second diatessaron $(9: 12=3: 4)$. The whole compass of this formation spans an octave $(6: 12=1: 2)$. In other words, these ratios describe the fixed parts of such an arrangement of tones, into which the moveable pitches - which will be placed in accordance with the required musical genus - must still be fitted. (And, as indicated before, such a complete scale arrangement will always comprise exactly eight notes within the octave.)

Now, the ratios of 6:8:9:12 are relatively easy to explain. However, most of the remaining numbers that make up the complete set of 1 to 12 (i.e. $1,2,3,4,5,7,10,11$ ) are more difficult, as many of them do not correspond to musical intervals. Kennedy may argue that this supports his thesis - that "disharmonious" intervals have negative meaning in the layout of Plato's texts—-but the musical problems go deeper than that: most of these ratios are not just disharmonious but musically meaningless. In order to explain this we need to delve into more technical elements.

\section{What does Kennedy's scale look like in musical terms?}

We can also unravel the problem from the other end: Kennedy presupposes a universal denominator 12 for his musical scale (which is better understood as a series of ratios). It 
is true that the factor 12 works well with a number of smaller figures to produce simple, and hence harmonious ratios. But this does not mean that the number 12 was habitually used in Pythagorean thinking as a basis against which intervals were identified.

To see why Kennedy's proposed scale is very different from the scales we find in Greek writers, let's go over what musical results Kennedy's scale would look like in terms of the musical intervals it would generate. For mathematical simplicity, let's set the bottom note of this series ${ }^{11}$ at $100 \mathrm{~Hz} .^{12}$

\begin{tabular}{lllll} 
No. & Ratio $/ \mathbf{1 2}$ & \multicolumn{2}{l}{ Frequency } & \multicolumn{2}{l}{ Semitones ${ }^{\mathbf{1 3}}$} & Closest musical interval \\
12 & $12 / 12=1$ & $100 \mathrm{~Hz} 0$ semitones & unison \\
11 & $11: 12$ & $109 \mathrm{~Hz}$ & $1.5 \mathrm{st}$ & midway btw. whole and half tone \\
10 & $10 / 12=5: 6$ & $120 \mathrm{~Hz}$ & $3.16 \mathrm{st}$ & minor third \\
9 & $9 / 12=2: 3$ & $133 \mathrm{~Hz}$ & $5 \mathrm{st}$ & perfect fourth \\
8 & $8 / 12=3: 4$ & $150 \mathrm{~Hz}$ & $7 \mathrm{st}$ & perfect fifth \\
7 & $7: 12$ & $171 \mathrm{~Hz}$ & $9.33 \mathrm{st}$ & very sharp major sixth \\
6 & $6 / 12=1: 2$ & $200 \mathrm{~Hz}$ & $12 \mathrm{st}$ & octave \\
5 & $5: 12$ & $250 \mathrm{~Hz} 15.16 \mathrm{st}$ & octave plus minor third \\
4 & $4 / 12=1: 3$ & $300 \mathrm{~Hz}$ & $19 \mathrm{st}$ & octave plus fifth \\
3 & $3 / 12=1: 4$ & $400 \mathrm{~Hz}$ & $24 \mathrm{st}$ & double octave \\
2 & $2 / 12=1: 6$ & $600 \mathrm{~Hz} 31 \mathrm{st}$ & & double octave plus fifth \\
1 & $1: 12$ & $1200 \mathrm{~Hz}$ & $43 \mathrm{st}$ & triple octave plus fifth
\end{tabular}

Put into musical notation, Kennedy's scale would look something like Example 2, with 12 corresponding to pitch $\mathrm{C}$ (the extended range of accidentals is used here, as in some contemporary music, to approximate tones that do not correspond exactly to any modern western pitch). 


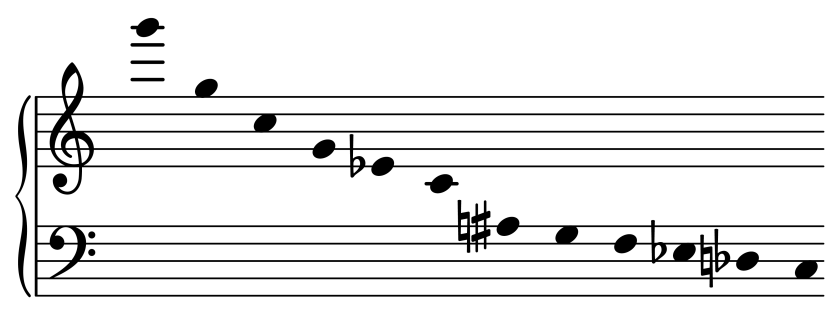

$\begin{array}{llllllllllll}1 & 2 & 3 & 4 & 5 & 6 & 7 & 8 & 9 & 10 & 11 & 12\end{array}$

\section{Ex. 2: Kennedy's scale results in unevenly spaced intervals.}

Even without technical knowledge of music it becomes apparent, when comparing Example 1 and 2, that musical intervals designed on ratios based on the number 12 produce a very different kind of scale. ${ }^{14}$ The intervals become progressively greater toward the first note of this extremely uneven series. The series in its entirety spans three and a half octaves - more than any one vocal part (or standard instrument) could reproduce. This is the where the difference between ratios and numbers, outlined above, becomes most pronounced: the succession of numerical divisions and the succession of musical intervals do not relate to each other linearly. Not only does this conglomeration of musical intervals not bear any resemblance to any scale systems that the Greeks theorized ${ }^{15}$ but it also makes for a very poor correspondence of the twelve equal parts of the texts that Kennedy's twelve-tone scale is meant to relate to.

The unevenness becomes particularly problematic when we also consider the "finegrained musical structure between the twelve notes" (p. 18) that Kennedy says is related to Plato's "so-called 'quarternotes' mentioned in the Republic at 531a4" (p. 18, n. 68). Kennedy sees significant divisions occurring at every quarter of each of his twelve "notes," is actually pyknomata ${ }^{17}$ (dense or compressed things), which in the context of the 
discussion may be considered to be equivalent to an enharmonic diesis (approximately the quarter of a 8:9 tone, hence often referred to as a "quartertone" in English). Nevertheless, there is no specific reference to a fraction of a quarter in this passage, and any association with quartertones is dependent on the specific idea of a tone (an 8:9 ratio or thereabout). Most of Kennedy's scale consists of intervals that are much larger than this $8: 9$ ratio.

Moreover, Plato specifically refers in the cited passage to such intervals by saying that some believe "that that is the smallest interval, by which measurement is to be made, while others take issue with them, saying that the notes sounded are already the same."18 In other words, the pyknomata are intervals so small that people argue whether the two notes are the same or not. In Kennedy's division, in contrast, a "quarternote" between notes 1 and 2 (an octave interval) would span approximately the interval of a minor third, which is much larger than even an entire standard whole tone. Clearly two pitches in such a large interval would not be mistaken for the same note, so connecting Plato's pyknomata with Kennedy's division is misleading. ${ }^{19}$

It is possible that Kennedy here is potentially relating his scale to the modern twelve-note equally divided chromatic scale, but even there each interval is a semitone. Twelve semitones per octave mean six whole tones per octave. There would thus be 24 quartertones in a theoretical division, not the 48 that Kennedy assumes. The ramifications of this mistaken assumption can be enormous when used as the basis for statistical analysis, since moving from a 12 -fold to a 48 -fold division makes it easy to find significant moments that line up with a dividing point. $^{20}$ 
But suppose we accept this very uneven set of twelve ratios as a potential "scale." Even if we ignore the great variation in musical interval size, mapping this scale onto an equal twelve-fold division of dialogues, with each section being "harmonious" or "disharmonious" is still not straightforward. Each note cannot itself be more or less "harmonious"; such a property only applies to an interval, that is, the ratio of two notes together. If we consider this collection of twelve notes to constitute a musical scale according to any Greek concept (or any modern concept of a musical scale), the harmoniousness of each note can be determined by its relationship to any other note in the scale. To continue the pie analogy mentioned above, any number of slices from a pie could be compared to any other number of slices in a ratio, not just to the whole pie.

For example, within the 6:8:9:12 set of four notes, there are not only the three relationships Kennedy mentions $(6: 12,8: 12,9: 12)$, but also three other potential interval ratios: another fourth $(6: 8=3: 4)$, another fifth $(6: 9=2: 3)$, and a whole tone $(8: 9){ }^{21}$ It is this full complement of interval relationships that mattered to Greek theorists. ${ }^{22}$ Kennedy asserts that the 8th note of the series is harmonious, because it creates an interval of a fifth with the 12 th note $(8: 12=2: 3)$, but the 8 th note could also be considered disharmonious with the 9th note. Within the entire set of 12 ratios, there are not just 12 potential intervals, but 78 , since every note can potentially be related to every other note (including itself, creating a unison). ${ }^{23}$ Most notes within the "scale" could be considered "harmonious" or "disharmonious" depending on the second note chosen to create the interval. In fact, there are 46 unique classes of musical intervals present among the twelve-note system Kennedy creates. ${ }^{24}$ 
In his interpretation, Kennedy disregards almost three-quarters of these potential relationships and only considers intervals created between some note and the $12^{\text {th }}$ note of the series, ${ }^{25}$ which allows him to declare individual notes to have harmonious or disharmonious properties. ${ }^{26}$ Such a restriction can only make sense if the starting point is Plato's text divided into twelve equal parts. From the viewpoint of music theory, this restriction is not only arbitrary but also lacks historical grounding; pitches within Greek systems were usually related to multiple other pitches within a scale system, thereby creating multiple intervals. The idea that one and only one pitch within a given scale could act as the only note against which all others are compared is not found in Pythagorean traditions in Greek musical thought. ${ }^{27}$

\section{Pythagoreans and Harmonicists}

As we have seen, "equal division" does not mean the same thing in spatial terms as it does in musical terms. As Kennedy argues, Plato's texts can be divided into twelve equal parts, and it seems that the closest equivalent in the musical domain to this spatial division of the text would be found in the equal spatial ${ }^{28}$ division of the monochord, a device much in use among Greek Theorists, and discussed in passing by Kennedy (p. 16, n. 62$)^{29}$

The monochord is nothing but a taut string that can be divided at various points along its length and then plucked to produce a pitch. By comparing pitches produced by different string lengths along the monochord, ratios can be determined. It became the most 
important mechanical device in music-theoretical teaching, comparable in many ways to the compass and ruler of ancient geometry.

An equal division of the monochord into any number of equal parts was a basic step in the lengthy process of constructing a scale, just as a simple division of a line segment or a bisection of an angle would be part of a more complex geometric proof. Equal divisions were generally used to locate a few intervals (for example, a 12-fold division allows the 6:8:9:12 Pythagorean construction of four notes), ${ }^{30}$ rather than to construct the scale itself, which usually required many stages of interval derivation by various methods. Furthermore, there is no evidence that a 12-fold division was part of standard Pythagorean constructions in Plato's time. ${ }^{31}$

Whether calculated through monochord constructions or other methods, the precise determination of intervals as numerical ratios was one of the chief occupations of music theory during Antiquity, and it was in the method employed to determine intervals that the two factions of Greek music theory, Pythagoreans and Harmonicists, clashed most sharply. ${ }^{32}$ Put simply, the Harmonicists took an empiricist approach and insisted that the ear was the ultimate arbiter over interval discrimination, whereas the Pythagoreans believed, true to form, that pure intervals had to correspond to certain numerical ratios.

Take the interval discussed earlier, the diatessaron or fourth, which demarcates the outer boundaries of the tetrachord. For Pythagoreans, this interval corresponds to the ratio 3:4. For Harmonicists, by contrast, the diatessaron is defined as two and a half tones. For all intents and purposes, this may seem like six of one and half a dozen of the other. But in reality there are subtle differences that divide both positions sharply from one another. 
To understand the difference let's take the Harmonicists' position in terms of ratios. Suppose we begin with a diatessaron with a ratio of approximately $3: 4$. The Harmonicist would envision that ratio divided into five equal parts, grouped into three segments - $\mathrm{a}$ whole tone ( 2 parts), a whole tone ( 2 parts), and a semitone ( 1 part $).{ }^{33}$ The only way to obtain a ratio for one of these parts would be to take the fifth root of 3:4 (which is tantamount to "dividing" this ratio by 5). This operation would obviously produce a set of irrational numbers. Rather than dealing in abstract ratios, the Harmonicist would rely on empirical evidence to divide the interval into segments where the whole tone sounded alike in size and the semitone sounded like half of a whole tone. While mathematically not exact, the intent was to produce a scale of even intervals.

This is different from a Pythagorean approach which would attempt to find ratios that could abstractly add up to 3:4. The early Pythagorean Archytas, for example, suggested a diatonic division of the diatessaron into a whole tone (8:9), an interval slightly larger than a standard whole tone (7:8), and an interval quite a bit smaller than a standard semitone (27:28). ${ }^{34}$ Multiplying these three ratios together (equivalent to adding the intervals) gives 3:4. Philolaus, another early Pythagorean, allowed two equal whole tones (8:9), but the remainder within the fourth was 243:256, an interval called the Pythagorean leimma, which is a bit smaller than a standard semitone. ${ }^{35}$ Although the last ratio appears complex, it is easily constructed on the monochord and, more importantly to the Pythagoreans, it is composed of rational numbers.

But, of course, for a Pythagorean an interval is never just an interval but an expression of universal principles. Numerical inaccuracies that seem perfectly legitimate to the Harmonicists, because they are all but inaudible, are therefore completely unacceptable to 
the Pythagoreans. A Harmonicist would not think twice about defining a semitone as the two equal halves of a whole tone, whereas Pythagoreans find it mathematically necessary in dividing a whole tone (8:9) to introduce a major (16:17) and a minor (17:18) semitone, the difference between which is perceptually negligible.

It is important to bear in mind the enormous philosophical gap between Harmonicists and Pythagoreans to keep Kennedy's musical argument in perspective. Kennedy's suggestion that Plato's secret twelve-tone scale may have been based on Harmonicist thinking (p. 17, n. 63) is complicated by the fact that the two camps saw that the differences in methodology between them posed insurmountable and irreconcilable obstacles. If Plato's views of music were Pythagorean, and there is good reason to believe they were, then he would hardly have relied on Harmonicist arguments. From the perspective of Kennedy's overall argument — that Plato has embedded a secret Pythagorean code in his dialoguesit therefore would seem important not to muddle these two traditions.

Chronology is a complicating factor here. The earliest of the Harmonicists whose writings we know is Aristoxenus of Tarentum, a student of Aristotle and a harsh critic of Pythagorean numerical principles. It seems that Aristoxenus was active in Tarentum during the later years of Plato's life. While Aristoxenus does refer to earlier harmonikoi, no earlier works have survived, and the question of the extent to which he began a genuinely new tradition of music-theoretical thought is a complex one. ${ }^{36}$

But no matter whether Plato was familiar with Aristoxenus' work itself, we can say with some confidence that the music theorists in Plato's circle - above all Archytas, also of Tarentum — were very much the kind of rationalist Pythagoreans from which the 
empiricist school of the Harmonicists was at pains to set itself off. Especially considering the discussions of music in the Republic, it seems safe to say that Plato did not associate his work with the Harmonicists.

\section{Music and Numbers in Plato}

There can be little doubt that numbers do matter in Plato's philosophy. Certainly from a music-theoretical viewpoint, Plato's allegiance to a Pythagorean worldview has hardly been under any doubt. The main problem with Kennedy's musical argument is that his stichometric calculations make it necessary for him to give heightened relevance to the factor 12, which, as we have seen, is an expedient number for his purposes but does not play a particularly prominent role in Pythagorean music-theoretical traditions.

Plato and the Pythagoreans in fact allude to other important numbers: for the Pythagoreans, the number 10 has great significance, as the tetractys, the mystical arrangement of points in rows of 1,2,3, and 4 elements so as to form a triangle, is based on this number. Orthodox Pythagorean traditions demand that musical ratios can only be formed from numbers taken from the tetractys (and their multiples).

Plato himself gives one important example of a musically significant number in the much-discussed "Myth of Er" of the Republic. Here, Plato famously writes about a group of eight sirens standing on the rim of the circles of the Spindle of Necessity, each singing a note of constant pitch, "and the eight notes together make up a single scale [mian harmonian]." (Rep., 10.617b). 
Finally, to find a Platonic musical scale derived from Pythagorean principles, we need look no further than a scale explicitly given by Plato himself in the Timaeus (35b-36c). Here Plato describes a system that Greek theorists related to an extension of the tetractys, the Pythagorean lambda, which is generally represented as sequences of powers of 2 $(1: 2: 4: 8)$ and 3 (1:3:9:27) descending along the two strokes of a Greek lambda. (Note that the number 12 in not a part of either series. ${ }^{37}$ )

Plato then adds the harmonic and arithmetic means (commonly used by the Pythagoreans to find important ratios within a musical interval) between each pair of numbers in each sequence. ${ }^{38}$ For example, between 1 and 2, the two means fall at 3:4 and 2:3, the fourth and the fifth within the octave $1: 2 .^{39}$ In the other series, for the octave plus fifth ratio between 1 and 3, the means fall at 2:3 and 1:2, the perfect fifth and octave. Similar calculations locate the means at the same musical intervals within the other octaves $(2: 4$, $4: 8)$ of the first series and the other octave plus perfect fifth ratios $(3: 9,9: 27)$ of the second series.

The series replicate the same patterns of intervals over and over, so it is instructive just to focus on one segment. Within the octave $1: 2$, divisions fall at $3: 4$ and $2: 3$. Such a division can also be represented by the 6:8:9:12 Pythagorean division used earlier, where the octave is $6: 12=1: 2$, the fourth is $6: 8=3: 4$, and the fifth is $6: 9=2: 3$. Note here that the standard of comparison for the scale is not 12 , the last note of the octave (as Kennedy assumes), but rather 6 , the first note. This is not to give priority to the intervals with the first note, but rather to point out that Greek scales were generally derived in a descending fashion, as can be seen in the gradually decreasing fractional values beginning at the unison $1: 1$, the fourth $3: 4$, the fifth $2: 3$, and finally the octave $1: 2$. 
Continuing with the Timaeus construction, Plato notes that his two series result only in intervals with the Pythagorean ratios 2:3, 3:4, and 8:9 (the whole tone). Again, unlike Kennedy's 12-ratio system, here all intervals are musically meaningful and in fact standard Pythagorean ratios. In the final division, Plato instructs that each 3:4 (diatessaron) interval within the scale should be filled in with two 8:9 standard whole tones, with the remainder being 243:256. (Recall that this division of the diatessaron is that of the early Pythagorean Philolaus, again demonstrating the Pythagorean heritage of Plato's system here.) Within the first 1:2 octave, represented by the 6:8:9:12 ratios, there are two 3:4 ratios - 6:8 and 9:12. Each of these is therefore divided into two whole tones and a 243:256 Pythagorean leimma.

Example 3 shows this pattern of intervals in the first octave, which is then repeated twice to complete Plato's first 1:2:4:8 series. ${ }^{40}$ White noteheads are used here to represent the fixed pitches of the tetrachords, and black noteheads represent the inner pitches, which are here filled in according to Plato's Pythagorean division of the tetrachord.

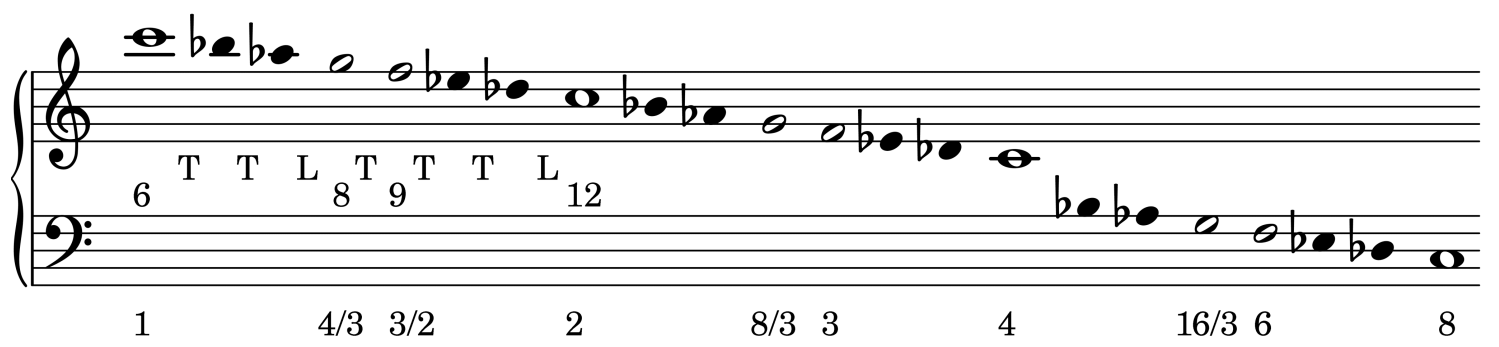

Ex. 3: A Pythagorean scale described in Plato's Timaeus 
There is some debate among scholars about the proper way to derive all the internal intervals in the second series, but whatever method is used, the scale must be constructed entirely according to early Pythagorean principles using only Pythagorean intervals. Like Kennedy's system, this scale spans many octaves, but that is the only point of resemblance. Plato's Pythagorean scale in the Timaeus contains no huge intervals, but it is also not an equally divided scale. If Plato were using a hidden Pythagorean musical scale within his dialogues, it would have to use similar principles as the Timaeus scale, which is a rational extension of Greek music theory and Pythagorean principles to create a system whose large span could represent the cosmos. 


\section{NOTES}

We wish to thank Michael Scott Cuthbert, David Elmer, Christopher Krebs, and Eric Nelson for their helpful comments on the text.

1 Ernest McClain, The Pythagorean Plato (Stony Brook, NY: Nicolas Hays, 1987), 5.

2 Pitch is the technical term for what is generally referred to as tone: a musical sound of definite height. ("Tone" often carries implications of other parameters, such as instrumental timbre, whereas pitch refers to the abstract dimension of tone height.)

3 Intervals describe the distance between two pitches.

4 A note on definitions may be helpful here. Harmony in its modern sense (to which Kennedy alludes here) indicates the "vertical" dimension of music, the way in which individual pitches can be put together and sounded simultaneously to form consonances and dissonances. (This concept of harmony is predicated on a systematic, generalizable scale.) Ancient Greek music did not know harmony in this sense: the Greek musical term harmonia connotes other scale-related concepts. Kennedy uses "harmonic" in the sense of the scale's capacity to generate intervals that can be expressed in terms of ratios.

5 The classics in Greek music theory include Andrew Barker, Greek Musical Writings, 2 vols. (Cambridge: Cambridge University Press, 1992); Martin West, Ancient Greek Music (Oxford: Clarendon Press, 1992), and Thomas Mathiesen, 
Apollo's Lyre: Greek Music and Music Theory in Antiquity and the Middle Ages (Lincoln: University of Nebraska Press, 1999).

6 Aristoxenus once asserts (El. harm. 57) that a perfect fourth interval could be considered to be equal in size to five semitones, but he only discusses this in the context of the relative size of intervals, not of the way scales could be constructed. Actual Greek musical scales could never contain such a division. Later writers also attribute to Aristoxenus (or to the Harmonicists) the idea that an octave was equal in size to six tones, and therefore in principle equal to twelve semitones, but again, such comparisons only described the relative magnitude of various intervals. These arguments, as will be seen below, were actually used by Harmonicists to attack the Pythagorean conception of intervals, which from the earliest times insisted on unequal divisions of all primary harmonious intervals, including the perfect fourth and the octave.

7 Tuning ratios are usually represented in modern scholarship with the larger quantity first, e.g., an octave is a 2:1 ratio and the perfect fifth a 3:2 ratio. Kennedy uses a less common convention of placing the smaller quantity first, so an octave is a $1: 2$ (or $6: 12$ ) ratio, a fifth $2: 3$, etc. The relationship between the two quantities is the same either way, since it makes no difference whether we measure an interval starting with the higher or the lower pitch. We adopt Kennedy's convention here to maintain consistency with the presentation of his arguments. 
8 The interval of the octave (or diapason) corresponds to the ratio $1: 2$, a double octave is, correspondingly, $(1: 2) \times(1: 2)=1: 4$.

9 The diatessaron corresponds to the ratio $3: 4$.

10 The standard whole tone corresponds to the ratio 8:9. Here, the word "tone" has a distinct technical usage within Greek theory to refer to an interval between two pitches, rather than a single pitch. Similarly, "semitone" and "quartertone" refer to intervals that are a half or a quarter of a tone, respectively.

11 Unlike modern musical scales, which tend to be represented as ascending, Greek systems are often derived in a descending manner, so note 12 in Kennedy's system is the lowest note of the scale. This can be seen from the ratios, which would be proportional to string lengths. For example, a 6:12 ratio compares a length of string 6 units long to a length 12 units long. Longer strings produce lower pitches, so in this octave ratio, the sound produced by the 12-unit segment is an octave below that produced by the 6-unit segment. Frequency is inversely proportional to string length, so in this example the shorter segment will vibrate twice as fast. If the 12-unit segment is $100 \mathrm{~Hz}$, the 6-unit segment will be $200 \mathrm{~Hz}$.

12 Pitches were not correlated with precise frequencies until the early modern age. Since we are only talking about intervals (ratios) here it makes no difference at which frequency we begin. The frequencies are merely a convenient way of examining the acoustical properties of a system tuned to the ratios of this scale.

13 The semitone measure used here is the same as modern 12-note equal temperament. While this unit would not be used by the Greeks in this exact form, 
it gives a consistent measure of the relative acoustical size of intervals as our ears perceive them, and as the Greek harmonic theory would evaluate the size of intervals. The number of standard equal 12-note equal-tempered semitones can be derived from the interval ratio by the equation $n=-12 \times(\log r / \log 2)$, where $r$ is the ratio expressed as a fraction. Intervals close to a whole number will sound similar to a modern musical interval.

14 There is one historical precedent that we are aware of that makes use of such a construct: Hugo Riemann's Geschichte der Musiktheorie (1898) interprets Arabic "messel" (mathal) theory so as to result in a similar looking series (notated in reverse order). Riemann's interpretation, however, has long been recognized as tendentious and historically inaccurate.

15 To be sure, the Greeks used pitches that we cannot represent faithfully in our modern notation system, especially in the enharmonic genus. The irregular pitches we arrive at here, however, have no systematic place in any of the ancient genera.

16 This interpretation is made clear by Kennedy's references to significant moments in dialogues occurring at the "six and a quarter twelfths point" or the "nine and three-quarters point" (p. 7, n. 26).

17 The standardized music-theoretical terms follow traditional conventions of transcription (hence pyknomata rather than puknomata). Since these spellings are the established terms in music theory, we will retain them here. See also Hagel, Ancient Greek Music, xviii. 
18 Rep. 531a, , tr. from Andrew Barker, Greek Musical Writings (Cambridge: Cambridge University Press, 1989), II: 55. Barker has put together all the most important sources on Greek music theory in this excellent anthology.

19 Even if it were easy to map quartertones onto Kennedy's system, their musical meaning would be indeterminate. Socrates himself derides the very concept of the pyknomata in the cited passage. Moreover, the earliest source for the details of the "close-packing" (katapyknosis) by the Harmonicists is Aristoxenus, who makes clear that such divisions had no musical meaning and did not constitute a scale per se, but were instead a sort of enumeration of all possible intervals that notes could fall into in all possible scalic systems. See Aristoxenus El. harm. 2728. The difficulty of mixing Harmonicist and Pythagorean ideas about scale will be discussed in the next section.

20 For example, a division of the 2400-line Symposium would create segments of 50 lines each. Kennedy at one point notes that his total line counts come out to round multiples of 12 "with about one to two percent accuracy" (pp. 9-10). One to two percent of 2400 lines is an error of 24 to 48 lines. If the segments are only 50 lines long, and accuracy within only a couple percent is required, any line could potentially line up with a significant division.

21 There are also four other ratios, since each note can create a unison (1:1) with itself. 
22 See Philolaus frag. 6. In one of the earliest statements of Pythagorean harmonic doctrine, Philolaus here enumerates all the interval relationships within the 6:8:9:12 proportion.

23 The number of combinations of size $\mathrm{k}$ drawn from a set of $\mathrm{n}$ elements is given by $\mathrm{n} ! /[\mathrm{k} ! \times(\mathrm{n}-\mathrm{k}) !]$. For this situation, we have a set of 12 notes, which we combine 2 at a time, thus $12 ! /[2 ! \times(12-2) !]=66$. Such combinations do not include unison intervals, which combine a note with itself in a 1:1 ratio. This adds 12 ratios to the total.

24 For example, 1:2, 2:4, 3:6, 4:8, 5:10, and 6:12 are all octave (1:2) ratios and are here counted within the same class of intervals.

25 Multiple passages on p. 17 of Kennedy's article imply that every note must be sounded with the twelfth note to determine its harmoniousness.

26 Kennedy declares the first and second notes "neutral," probably because such enormous intervals go beyond the double octave (1:4) generally described by Greek music theory, and therefore we do not know whether they would be considered harmonious or disharmonious. Nevertheless, the Harmonicist Aristoxenus refers to experiments where he compared the sounds of two instruments with different ranges and was able to discover that the double octave plus fifth (Kennedy's second note) was concordant, as well as the triple and quadruple octave (though he does not mention the triple octave plus fifth, Kennedy's first note ratio). See Aristoxenus, El. harm. 20-21. 
27 From a practical musical standpoint, this system would imply that each note is only ever heard in relationship to the twelfth note. A performance in such a scale would necessarily consist of constant returns to the twelfth note after any other note in the scale is played, since other melodic motions between notes would produce intervals that could be judged as harmonious or not. Given the huge intervals between the twelfth note and the first few notes of the scale, such a performance would be impossible to play on standard instruments and would sound quite unusual within the context of Greek music.

28 This equal spatial division of the monochord is, as seen, distinctly different from any equal musical division.

29 His statement, cited earlier, that "[a]ccording to Greek theory, the third (1:4), fourth (1:3), sixth (1:2), eighth (2:3), and ninth (3:4) notes on the twelve-note scale will harmonise with the twelfth" implies an explanation conceptually indebted to the monochord. Moreover, this is perhaps the only explanation for disregarding most of the potential intervals in his system, while only focusing on relationships to 12 (which would represent the entire string). Even on a monochord, however, one does not necessarily relate a segment to the entire string; it could be related to the sound of another segment.

30 Although a 12-fold division of the monochord could line up with Kennedy's system of ratios, the "harmonious" properties that Kennedy ascribes to both ratios and portions of dialogues would map only onto the dialogues at exact division points. Only some string lengths at those exact division points in the 12-fold 
division (such as $8: 12$ or 9:12) on the monochord are harmonious when compared to the entire string; the lengths between them are almost uniformly disharmonious. In contrast, Kennedy associates the segments of a dialogue between division points with the properties of the division points themselves, so the segment between notes 8 and 9 , for instance, is considered entirely harmonious for him. In effect, equating such large segments with infinitesimal points is like confusing a slice of pie with the cut that divides it from the rest of the pie, to use our earlier analogy.

31 See David Creese, The Monochord in Ancient Greek Harmonic Science (Cambridge: Cambridge University Press, 2010). Creese's recent comprehensive history of the monochord only once mentions the idea of a standard 12-fold division, and even there it is only presented as an inaccurate assumption by a previous scholar. Based on the scant evidence for any standard division, Creese speculates that a "twelve-unit monochord may have been standard—if there was ever such a standard—by the time of Thrasyllus" (p. 103, n. 76) who died in 36 C.E. There is no evidence of such a standard division in the time of Plato, and in fact Creese argues that "[n]one of the arguments for a pre-Aristotelean date for the monochord are convincing" (p. 102), thereby questioning whether the monochord even existed during Plato's lifetime.

32 One potential source of confusion may arise from the fact that the field of study was known as "Harmonics." Only one faction of its practitioners, however, would consider themselves to be "Harmonicists." 
33 The following examples assume what the Greeks referred to as a diatonic division of the tetrachord. Other types of divisions were possible, but the diatonic is often the simplest and ultimately the one Plato adopts in his own Pythagorean scale in the Timaeus, as will be described in the next section.

34 See Ptolemy, Harm. 30.9-31.18, tr. in Barker, Greek Musical Writings II: 43-5.

35 Philolaus frag. 6, tr. in Barker, Greek Musical Writings II: 36-8. In this fragment, Philolaus also clearly states that the octave is irregularly divided into five tones and two dieses, instead of the equal six-tone division that was sometimes attributed to the Harmonicists.

36 See Aristoxenus El. harm. 2.28-30. Aristoxenus mentions Epigonos, Eratokles and his pupils, as well as the supporters of Pythagoras of Zakynthos and Agenor of Mytilene. See Andrew Barker, The Science of Harmonics in Classical Greece (Cambridge: Cambridge University Press, 2007), esp. Chapter 2: "Empirical harmonics before Aristoxenus."

37 In fact, the number 12 is not present in the entire construction of means that is described below. The pitch that falls at the number 12 is not generated by Plato's literal instructions for constructing the scale, though some interpretations would interpolate the pitch along with the various tones and leimmata.

38 For two numbers $x$ and $y$, the arithmetic mean is $(x+y) / 2$ and the harmonic mean is $2 /(1 / x+1 / y)$. To divide the ratio in half exactly would require the geometric mean, the square root of $x * y$. 
39 For $\mathrm{x}=1 / 1$ and $\mathrm{y}=1 / 2$, the arithmetic mean is $(1 / 1+1 / 2) / 2=(3 / 2) / 2=3 / 4$.

The harmonic mean is $2 /[1 /(1 / 1)+1 /(1 / 2)]=2 /(1+2)=2 / 3$. For comparison, the geometric mean (an equal division) would be 1 divided by the square root of 2, the unharmonious interval of a tritone.

40 The interval pattern of tones (T) and leimmata (L) is given for the first octave. The bottom note of the example is again set to the pitch $\mathrm{C}$, to allow a comparison with Kennedy's scale given earlier. 